\title{
Influence of Interfacial Inter-metallic Compounds on the Electrical Characterization of Cu/Al Joints Produced by Flash Welding and Diffusion Brazing
}

\author{
Xue-Gang Wang * (D, Xing-DongYuan ${ }^{a}$, Jia-Ning Li ${ }^{a}$, Xin-Geng Li $^{b}$ \\ ${ }^{a}$ Shandong Jianzhu University, School of Materials Science and Engineering, Jinan, 250101, China \\ ${ }^{b}$ State Grid Shandong Electric Power Research Institute, Jinan, 250002, China
}

Received: July 19, 2020; Revised: September 8, 2020; Accepted: September 13, 2020

\begin{abstract}
The aim of this study was to clarify the influence of inter-metallic compounds (IMCs) on the electrical conductivity of $\mathrm{Cu} / \mathrm{Al}$ joint. The longitudinal resistance and the lateral current distribution at flash welded and diffusion brazed $\mathrm{Cu} / \mathrm{Al}$ joint interfaces were investigated using four-point method and conductive atomic force microscopy, respectively. $\mathrm{A} 2 \mu \mathrm{m} \mathrm{Cu}_{9} \mathrm{Al}_{4} / \mathrm{CuAl}_{2}$ layer was formed in both joints. The IMCs layer was homogenous and the current distribution interface was planar at diffusion brazed joint. However, the IMCs layer was discontinuous and the current distribution interface was non-planar at flash welded joint. After heat treatment at $350^{\circ} \mathrm{C}$ for $500 \mathrm{~h}$, the thickness of interfacial layer was increased to $50 \mu \mathrm{m}$. $\mathrm{CuAl}$ and a short crack were newly formed in the diffusion brazed joint. $\mathrm{CuAl},(\mathrm{Cu}, \mathrm{Al})_{\mathrm{x}} \mathrm{O}_{\mathrm{y}}$ and a long crack were newly formed in the flash welded joint. A multilayer current distribution was found at both heat treated joints. The resistivity of all $\mathrm{Cu} / \mathrm{Al}$ joints was higher than that of copper and lower than that of aluminum. The resistivity of diffusion brazed joint was the lowest, which was lower than the theoretical value. The resistivity of the heat treated flash welded joint was the highest among all the joints.
\end{abstract}

Keywords: copper, aluminum, inter-metallic compounds, electrical resistivity, conductive atom force microscopy.

\section{Introduction}

$\mathrm{Cu} / \mathrm{Al}$ bimetal joints have been widely used to transmit the electricity in a variety of electrical applications, such as transmission grid ${ }^{1}$, high direct-current bus systems ${ }^{2}$ and electric vehicles ${ }^{3,4}$. In these applications, the electrical resistance of these $\mathrm{Cu} / \mathrm{Al}$ joints should be kept as low as possible to minimize the loss of electrical energy. Copper and aluminum have a high chemical affinity to each other. It is easy to form inter-metallic compounds (IMCs) at temperature above $120^{\circ} \mathrm{C}^{2}$. These IMCs have higher electrical resistivity than copper and aluminum. The electrical characterization of the $\mathrm{Cu} / \mathrm{Al}$ joints is then affected by the presence of the IMCs. It is difficult to avoid the IMCs during welding process and practical running. The IMCs can be controlled by adjusting the welding conditions during welding production. However, the current transmitted during service will increase the joint temperature and cause the nucleation and growth of $\mathrm{IMCs}^{5-7}$. As noted by Khanzadeh Gharah Shiran $\mathrm{MR}^{8}$, the higher thermal cycle temperature and longer thermal cycle times can cause the appreciable growth of interfacial IMCs layer in multilayer $\mathrm{Cu} / \mathrm{Al} / \mathrm{Cu}$ explosive welded joints. The formation of IMCs in service can affect the running life of $\mathrm{Cu} / \mathrm{Al}$ joint. Therefore, it is important to understand the influence of IMCs on the electrical characterization of $\mathrm{Cu} / \mathrm{Al}$ joint.

Many studies have shown that the resistance of $\mathrm{Cu} / \mathrm{Al}$ joint is linearly related to the thickness of IMCs layer, as shown in the Formula $1^{2,5,6}$.

*e-mail: wxuegang@163.com

$\frac{R_{f}-R_{0}}{R_{0}}=A \cdot x$

where $R_{f}$ is final resistance, $R_{o}$ is original resistance, $x$ is the thickness of the IMCs, $\mathrm{A}$ is the coefficient related to the welding method, such as $\mathrm{A}=0.4^{5}$ or $0.48^{6}$ in friction welding, and $\mathrm{A}=0.44^{2}$ in cold roll welding. It can be seen from Formula 1 that the electrical resistance of $\mathrm{Cu} / \mathrm{Al}$ joint is increased linearly with the thickness of IMCs. In addition, the influence of the IMCs on the electrical characterization is related to the welding method. Further research shows that the electrical resistance of the $\mathrm{Cu} / \mathrm{Al}$ joint is not affected significantly by the thickness of the IMCs if its thickness is lower than the critical thickness. The critical thickness of the IMCs depends on the welding method, such as $2 \mu \mathrm{m}$ for friction welding ${ }^{5-7}$, ultrasonic welding ${ }^{9}$ and diffusion bonding ${ }^{10}, 5 \mu \mathrm{m}$ for explosive welding ${ }^{11}$. That is to say, the thin IMCs cannot increase the resistance of $\mathrm{Cu} / \mathrm{Al}$ joint.

The interfacial IMCs in the $\mathrm{Cu} / \mathrm{Al}$ joints are usually lamellar or dispersed due to different welding methods. For example, the IMCs are dispersed in friction stir welded, ultrasonic welded and explosive welded $\mathrm{Cu} / \mathrm{Al}$ joints ${ }^{4,8,11}$. The IMCs are lamellar in diffusion bonded and flash welded $\mathrm{Cu} / \mathrm{Al}$ joints ${ }^{2,5,6,11}$. Since it is difficult to calculate the thickness of the dispersed IMCs, it is impossible to use Formula 1 to clarity its effect on joint resistance. A volume fraction of the IMCs is then used to express its effect on joint resistivity, as shown in the Formula $2^{12}$. 


$$
\frac{1}{\rho_{\text {total }}}=\frac{f_{A l}}{\rho_{A l}}+\frac{f_{C u}}{\rho_{C u}}+\frac{f_{I M C}}{\rho_{I M C}}
$$

where $\rho_{\text {total }}$ is the resistivity of $\mathrm{Cu} / \mathrm{Al}$ bimetal, $\rho_{\mathrm{Al}}$ is the resistivity of $\mathrm{Al}, \rho_{\mathrm{Cu}}$ is the resistivity of $\mathrm{Cu}, \rho_{\mathrm{IMC}}$ is the resistivity of IMCs, $f_{A l}$ is the volume fraction of $\mathrm{Al}$ in $\mathrm{Cu} / \mathrm{Al}$ bimetal, $\rho_{\mathrm{Cu}}$ is the volume fraction of $\mathrm{Cu}$ in $\mathrm{Cu} / \mathrm{Al}$ bimetal, $\mathrm{f}_{\mathrm{IMC}}$ is the volume fraction of IMCs in $\mathrm{Cu} / \mathrm{Al}$ bimetal. Similarly, the resistivity of the $\mathrm{Cu} / \mathrm{Al}$ bimetal is increased with the volume fraction of the IMCs. However, the resistivity of the $\mathrm{Cu} / \mathrm{Al}$ bimetal prepared by restacking drawing method is not significantly affected by the existence of IMCs when their volume fraction remains lower than $12 \%{ }^{12}$. Moreover, the resistivity of friction stir spot welds is lower than the theoretical value where there are no IMCs in the joint ${ }^{13}$. The laser beam vacuum welded $\mathrm{Cu} / \mathrm{Al}$ joint has electrically long term stable even with a few of IMCs ${ }^{14}$. That is to say, a small amount of IMCs will not cause the changes of joint resistance.

As mentioned above, a thick IMCs layers or a high content of IMCs can increase the resistance of the $\mathrm{Cu} / \mathrm{Al}$ joint. It is easy to understand that a thick layer or more IMCs can lead to high electrical resistance based on the Ohm's law. However, a thin IMCs layer or a small amount IMCs does not increase the electrical resistance of the $\mathrm{Cu} / \mathrm{Al}$ joint. Few works have been done to explain this abnormal phenomenon. These resistance data both in Formula 1 and Formula 2 are measured by using a four-point method with micro-ohmmeter test. It is very hard to detect the variation of electrical resistance by micro-ohmmeter when the thicknesses of the IMCs is lower than some certain thickness (certainly $<1 \mu \mathrm{m})^{15}$. According to Matthiessen's rule, the resistivity of metals can usually be changed by the structural defects, such as phases, dislocations, grain boundaries, residual stresses and strain fields. As noted by Shankar $\mathrm{S}^{16}$, the electrical characteristic of the $\mathrm{Cu} / \mathrm{Al}$ joint is affected by the phase type, thickness and content of the IMCs. Therefore, it is very necessary to use a new method to analyze the influence of the IMCs on the electrical characterization of the $\mathrm{Cu} / \mathrm{Al}$ joint from the micro view.

Conductive atomic force microscopy (CAFM) is a powerful tool to investigate the currents distribution with nano-scale of micro-scale resolution. It has been employed to detect the conductivity of different interfaces, such as metal/oxide interface $\mathrm{e}^{17,18}$, metal/semiconductor interface ${ }^{19}$ and semiconductor heterostructure ${ }^{20}$. In this study, CAFM was firstly used to reveal the current distribution across the $\mathrm{Cu}$ / Al joint from the microscopic perspective. The influence of the IMCs on the electrical characterization of the $\mathrm{Cu} / \mathrm{Al}$ joint was deeply investigated from the perspective of longitudinal resistance and lateral current distribution.

\section{Materials and Methods}

The base metals used in this work were commercial pure aluminum plate and pure copper plate with faying surface of $50 \mathrm{~mm} \times 5 \mathrm{~mm}$. Composition and material properties obtained by tensile test and micro-ohmmeter test are shown in Table 1. Two kinds of $\mathrm{Cu} / \mathrm{Al}$ joints with a length of $110 \mathrm{~mm}$ were prepared by flash welding and diffusion brazing, in which the length of the copper side was $50 \mathrm{~mm}$ and the length of the aluminum side was $60 \mathrm{~mm}$, as shown in Figure 1. The flash welded $\mathrm{Cu} / \mathrm{Al}$ joint was a common commercial product in the electrical industry. The $\mathrm{Cu}$-plate and $\mathrm{Al}$-plate were brought slowly together until they just touched. A high current flowed through the points of contact, rapidly heating and melting the metal at these points. The average burning rate and burning time is about $4.55 \mathrm{~mm} / \mathrm{s}$ and $5.3 \sim 5.6 \mathrm{~s}$, respectively. The molten metal was then expelled by its own rapid expansion. When the temperature was greater than the forging temperature, $\mathrm{Cu}$-plate and Al-plate were rapidly pushed together with an upset speed of around $132 \mathrm{~mm} / \mathrm{s}$. The high speed upset expelled remaining molten metal and then forged copper and aluminum together as shown in Figure 1a. The diffusion brazed $\mathrm{Cu} / \mathrm{Al}$ joint was prepared according to the method described in our previous works ${ }^{10,21 \text {, }}$ ${ }^{22}$. After arranging an aluminum alloy foil between $\mathrm{Cu}$-plate and Al-plate, they were pressed for axial direction with a pressure of $4 \mathrm{MPa}$ and then induction heated. A chromel/ type $\mathrm{K}$ thermocouple was spot-welded onto the outside edges of the Al plate for temperature control as shown in Figure 1b. During induction heating, the faying area was covered by argon flux to prevent the oxidation. A diffusion

Table 1. Composition and properties of materials used

\begin{tabular}{cccc}
\hline & Chemical composition $(w t \%)$ & Tensile strength $(\mathrm{MPa})$ & Resistivity $\left(10^{-9} \Omega \cdot \mathrm{m}\right)$ \\
\hline $\mathrm{Cu}-\mathrm{C} 11000$ & $(\mathrm{Cu}+\mathrm{Ag}) \geq 99.9 \%$ & 296 & 17 \\
\hline $\mathrm{Al}-\mathrm{AA} 1060$ & $\mathrm{Al} \geq 99.6 \%$ & 60 & 29 \\
\hline
\end{tabular}

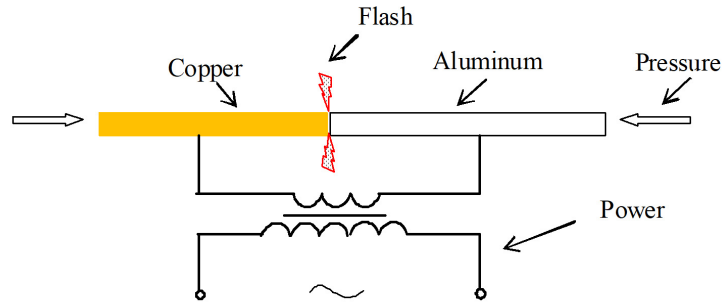

(a) Flash welding

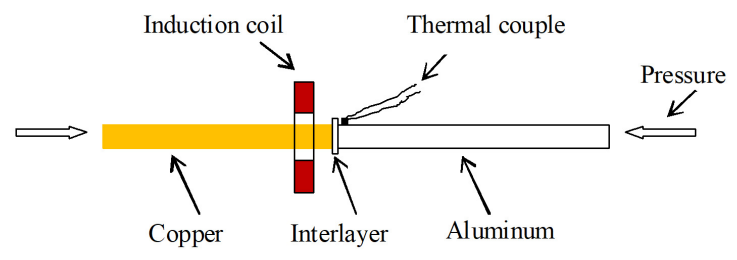

(b) Diffusion brazing

Figure 1. Sketch of $\mathrm{Cu} / \mathrm{Al}$ butt joints made by different welding methods: (a) Flash welding; (b) Diffusion brazing. 
brazed joint was made after holding at $600^{\circ} \mathrm{C}$ for $2 \mathrm{~s}$ under a pressure of $9 \mathrm{MPa}$.

Although the running temperature of transmission grid is generally in the range of $100^{\circ} \mathrm{C} \sim 150^{\circ} \mathrm{C}$, the actual temperature will exceed $200^{\circ} \mathrm{C}$ when the transmission grid is overloaded. Early work has found that the electrical resistance of flash welded $\mathrm{Cu} / \mathrm{Al}$ joint was not affected practically by thermal treatment from 2 years at $149^{\circ} \mathrm{C}$ to $5 \mathrm{~min}$ at $371^{\circ} \mathrm{C}^{5-}$ ${ }^{7}$. In this study, a heat treatment at $350^{\circ} \mathrm{C}$ for $500 \mathrm{~h}$ was introduced to investigate the electrical characterization of flash welded and diffusion brazed $\mathrm{Cu} / \mathrm{Al}$ joints. The samples of $110 \mathrm{~mm} \times 12 \mathrm{~mm} \times 5 \mathrm{~mm}$ were machined from both welded joints and then heated in an electric furnace. Three parallel samples were used for each heat treatment process.

The electrical resistance of $\mathrm{Cu} / \mathrm{Al}$ joint was measured by using a traditional four-point method with a microohmmeter, as shown in Figure 2. A direct current (DC) of 200A was passed from the copper side to aluminum side and the potential difference between two certain points was then measured automatically. So the electrical resistance was obtained by dividing the potential difference by passing current. The resistivity was calculated from the well known Formula 3.

$$
\rho=\frac{R \times S}{L}
$$

where $\rho$ is the resistivity, $R$ is the electrical resistance, $S$ is the cross sectional area and equals to $5 \mathrm{~mm} \times 12 \mathrm{~mm}, \mathrm{~L}$ is the length and equals to $100 \mathrm{~mm}$. Each reported resistivity represents an average of three tests. The current distribution images on the surface of $\mathrm{Cu} / \mathrm{Al}$ joint were collected using a Bruker Dimension EDGECAFM. The CAFM measurements were performed in a contact mode employing a SIC-PIC probe. A fixed DC bias $(-10 \mathrm{~V} \sim 10 \mathrm{~V})$ was applied between the tip and the sample. The current distribution maps were then obtained by scanning the joint step by step, as shown in Figure 3. The current amplitude of $\mathrm{Al}$, IMCs and $\mathrm{Cu}$ is different due to their different resistivity. The influence of IMCs on joint conductivity can be obtained by comparing the current amplitude in CAFM map. The cross sections of all $\mathrm{Cu} / \mathrm{Al}$ joints were analyzed by Scanning Electron Microscope (SEM). The fracture of some $\mathrm{Cu} / \mathrm{Al}$ joints was

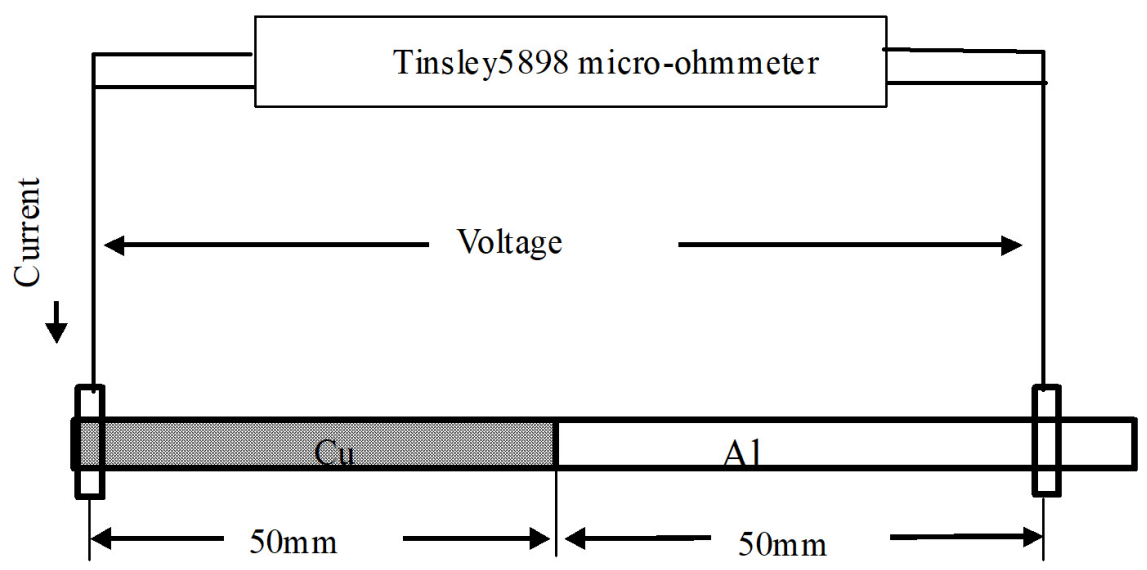

Figure 2. Schematic diagram of resistance test by micro-ohmmeter.

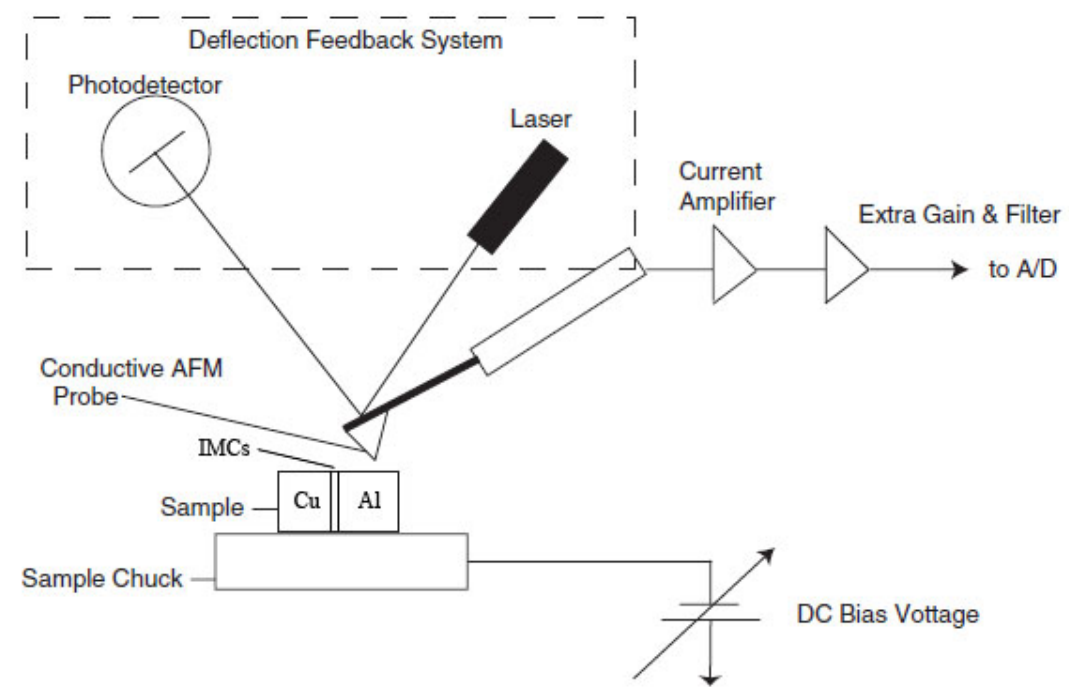

Figure 3. Schematic diagram of current map measurement by CAFM. 
tested by X-ray diffraction (XRD) to identify the crystal phase. Residual stress was measured using a Rigaku MSF3M X-ray machine. The spectral line of $\mathrm{K}_{\alpha}$ and $\mathrm{K}_{\beta}$ with chromium target was selected for copper side and aluminum side, respectively. Each reported residual stress represents an average of three tests.

\section{Results and Discussion}

\subsection{Diffusion brazed Cu/Al joints}

The microstructure and current distribution map of diffusion brazed $\mathrm{Cu} / \mathrm{Al}$ joint are shown in Figure 4. Two homogenous thin IMCs layers are found between copper and aluminum in the joint. $\mathrm{XRD}$ results show that $\mathrm{Cu}_{9} \mathrm{Al}_{4}$ forms on copper side and $\mathrm{CuAl}_{2}$ forms on aluminum side, as shown in Figure 5. The total thickness of the two IMCs layers is about $2 \mu \mathrm{m}$. As seen in Figure 4b, a planar current distribution interface is found on the current distribution map. The current map on copper side is shown in dark color, indicating high conductivity. While the current map on aluminum side is shown in light yellow, showing low conductivity. This is consistent with that the conductivity of copper is higher than that of aluminum. No obvious current distribution can be found on the surface of IMCs, indicating that the homogenous thin IMCs layer don't change the current distribution between copper and aluminum.

The microstructure and current map of diffusion brazed $\mathrm{Cu} / \mathrm{Al}$ joint after heat treated at $350^{\circ} \mathrm{C}$ for $500 \mathrm{~h}$ are shown in

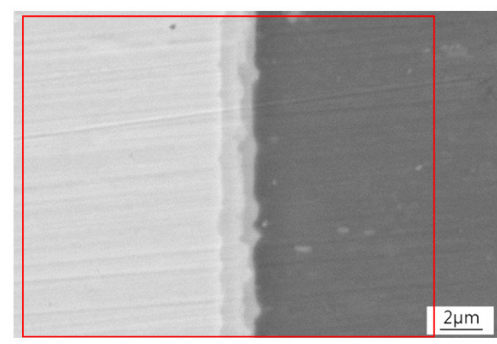

(a)SEM
Figure 6. Three IMCs layers are found between copper and aluminum in the joint. XRD results show that those IMCs between copper and aluminum are $\mathrm{Cu}_{9} \mathrm{Al}_{4}, \mathrm{CuAl}$ and $\mathrm{CuAl}_{2}$, as shown in Figure $6 \mathrm{c}$ and Figure $6 \mathrm{~d}$. The total thickness of those IMCs layers is about $50 \mu \mathrm{m}$. Different from the current maps of original diffusion brazed $\mathrm{Cu} / \mathrm{Al}$ joint, a multilayer current distribution between copper and aluminum is found on the heat treated $\mathrm{Cu} / \mathrm{Al}$ joint. This indicates that a thick IMCs layer changes the current distribution between copper and aluminum and then affects the electrical conductivity. Moreover, a short crack occurs in the middle of IMCs layers and the current distribution is different from the zone without crack. This indicates that crack can also change the current distribution and then affect the electrical conductivity.

\subsection{Flash welded Cu/Al joints}

The microstructure and current map of flash welded $\mathrm{Cu} / \mathrm{Al}$ joint are shown in Figure $7 \mathrm{a}$ and Figure $7 \mathrm{~b}$. A $2 \mu \mathrm{m}$ thin IMCs layers composed of $\mathrm{Cu}_{9} \mathrm{Al}_{4}$ and $\mathrm{CuAl}_{2}$ are found between copper and aluminum in the joint, as shown in Figure $7 \mathrm{c}$ and Figure $7 \mathrm{~d}$. Different from the IMCs in the diffusion brazed joint, the thickness of $\mathrm{CuAl}_{2}$ is higher than that of $\mathrm{Cu}_{9} \mathrm{Al}_{4}$ and the growth of $\mathrm{CuAl}_{2}$ is discontinuous in the flash welded joint. Similar to that in the diffusion brazed joint, the copper side exhibits high conductivity with dark current map and the aluminum side exhibits low conductivity with light yellow current map. However, the current distribution interface is non-planar which is different from that of diffusion brazed

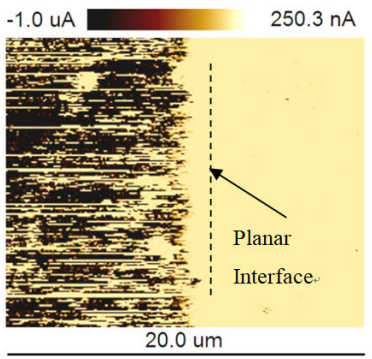

(b)CAFM analysis result in the red rectangle of SEM image

Figure 4. Microstructure and current distribution map of diffusion brazed $\mathrm{Cu} / \mathrm{Al}$ joint: (a) SEM; (b) CAFM analysis result in the red rectangle of SEM image.

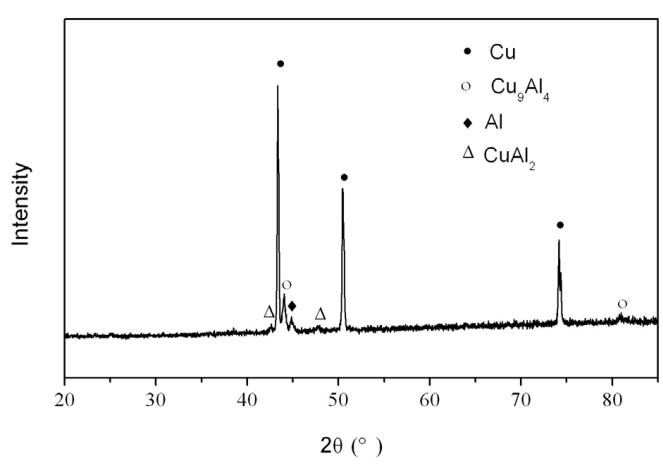

(a) $\mathrm{Cu}$ side

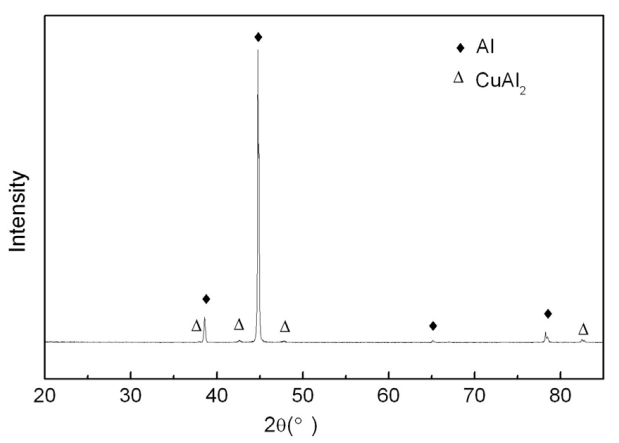

(b) Al side

Figure 5. XRD of diffusion brazed $\mathrm{Cu} / \mathrm{Al}$ joint: (a) $\mathrm{Cu}$ side; (b) $\mathrm{Al}$ side. 


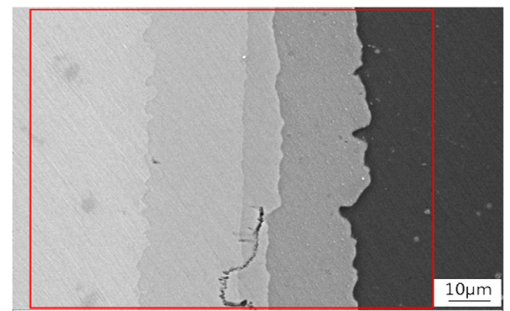

(a)SEM

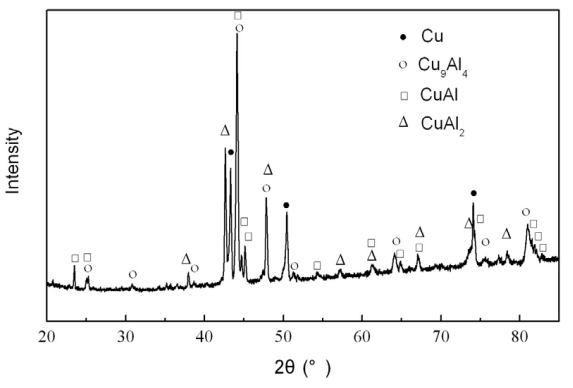

(c) XRD of $\mathrm{Cu}$ side

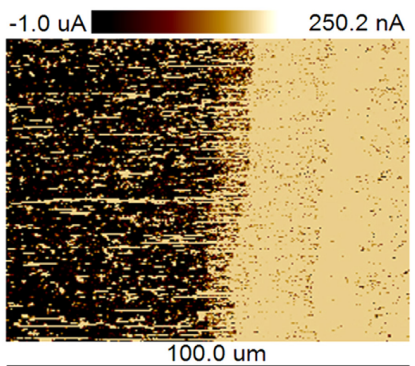

(b)CAFM analysis result in the red rectangle of SEM image

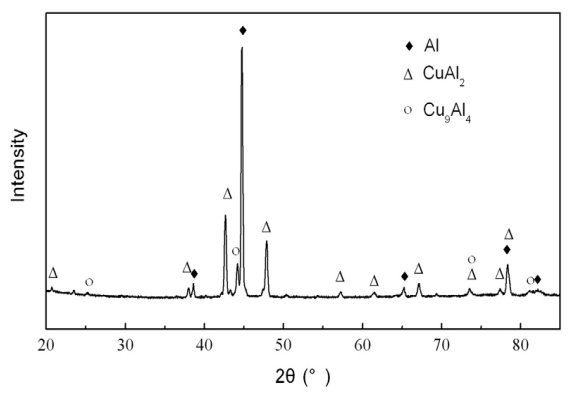

(d)XRD of $\mathrm{Al}$ side

Figure 6. SEM, CAFM and XRD results of diffusion brazed $\mathrm{Cu} / \mathrm{Al}$ joint after heat treatment at $350^{\circ} \mathrm{C}$ for $500 \mathrm{~h}$ : (a) SEM; (b) CAFM analysis result in the red rectangle of SEM image; (c) XRD of Cu side; (d) XRD of Al side.

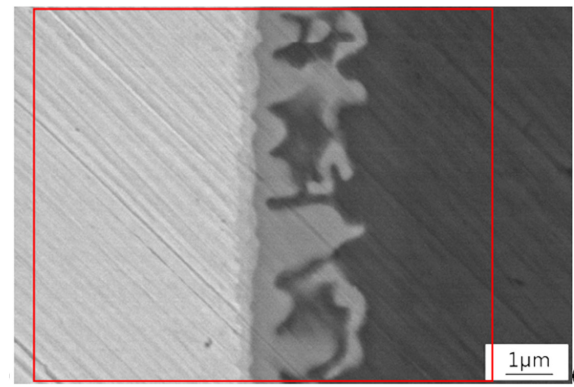

(a) SEM

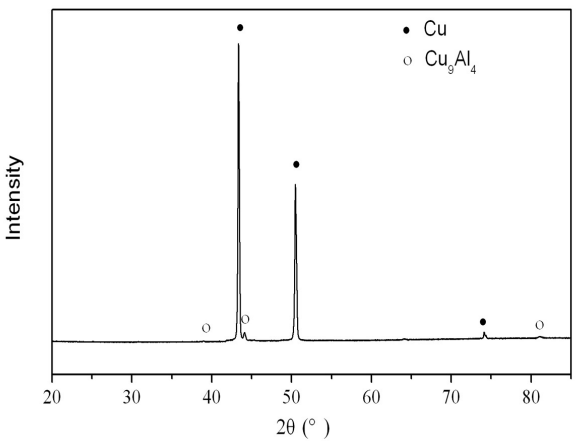

(c) XRD of $\mathrm{Cu}$ side

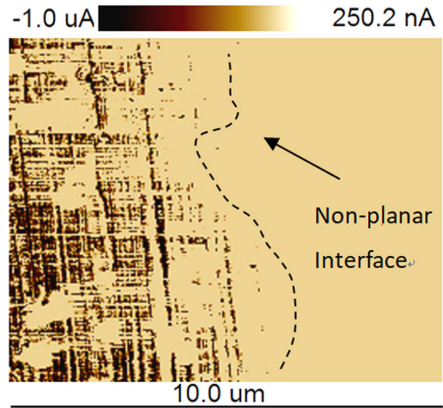

(b)CAFM analysis result in the red rectangle of SEM image

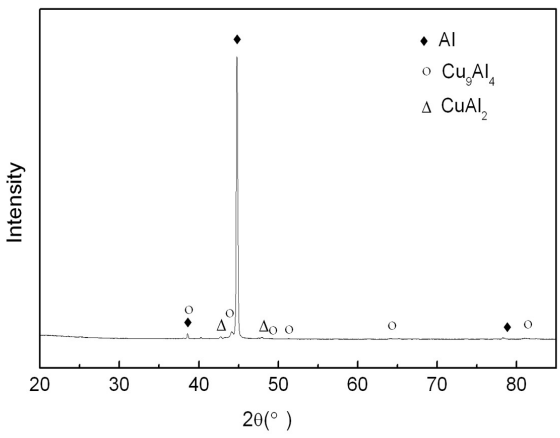

(d )XRD of Al side

Figure 7. SEM,CAFM and XRD results of flash welded $\mathrm{Cu} / \mathrm{Al}$ joint: (a) SEM; (b) CAFM analysis result in the red rectangle of SEM image; (c) XRD of $\mathrm{Cu}$ side; (d) XRD of Al side. 
joint. This indicates that the discontinuous thin IMCs lead to a wave distribution of current between the copper and the aluminum.

The microstructure and current map of flash welded $\mathrm{Cu} /$ $\mathrm{Al}$ joint after heat treated at $350^{\circ} \mathrm{C}$ for $500 \mathrm{~h}$ are shown in Figure 8. A $50 \mu \mathrm{m}$ thick interfacial layer is found between copper and aluminum in the joint. The interfacial layer consists of a composite layer of $(\mathrm{Cu}, \mathrm{Al}){ }_{\mathrm{x}} \mathrm{O}_{\mathrm{y}}$ and $\mathrm{Cu}_{9} \mathrm{Al}_{4}$, $\mathrm{CuAl}$ layer and $\mathrm{CuAl}_{2}$ layer as shown in Figure 9. A long crack parallel to $\mathrm{Cu} / \mathrm{Al}$ interface occurs near the copperas shown in Figure 8a. The current distribution interface is a non-planar interface between the dark current map and the light yellow current map. As seen in the three rectangles in Figure $8 b$, some current distribution points are also found on the surface of IMCs and aluminum, indicating a multilayer current distribution. Compared with the results in Figure 6b, the presence of long crack and oxide in the joint can also change the current distribution between copper and aluminum.

\subsection{Electrical resistance}

Figure 10 shows the variation of $\mathrm{Cu} / \mathrm{Al}$ joint resistivity with heat treatment time at $350^{\circ} \mathrm{C}$. The joint resistivity is increased with the heat treatment time for both joints. During the heat treatment at $350^{\circ} \mathrm{C}$, the resistivity of diffusion brazed $\mathrm{Cu} / \mathrm{Al}$ joint is always lower than that of flash welded $\mathrm{Cu} / \mathrm{Al}$ joint. This indicates that diffusion brazing can provide more stable service life than flash welding.

The resistivity of $\mathrm{Cu} / \mathrm{Al}$ joints with and without $500 \mathrm{~h}$ heat treatment as well as copper and aluminum are shown in Figure 11. The theoretical value of $\mathrm{Cu} / \mathrm{Al}$ joint resistivity is also calculated according to Formula 2 where $\mathrm{f}_{\mathrm{IMC}}=0^{2,12}$, $\mathrm{f}_{\mathrm{Cu}}=50 \%, \mathrm{f}_{\mathrm{Al}}=50 \%$. It means that the conductivity of the joint is as good as the specimen without a connecting joint when its resistivity is equal to theoreticalvalue ${ }^{14}$. It can be seen that the electrical resistivity of $\mathrm{Cu} / \mathrm{Al}$ joints with and without heat treatment was higher than that of copper and lower than that of aluminum. Diffusion brazing leads to the minimum resistivity of $\mathrm{Cu} / \mathrm{Al}$ joint which is lower than theoretical resistivity. The resistivity of others joints is higher than the theoretical resistivity.

It is well known that the resistivity of IMCs is higher than that of copper and aluminum. The relationship among them is shown in Formula 4. In order to better characterize the effect of IMCs on the joint resistivity, a theoretical resistivity is introduced in many published literatures. An ideal joint is defined when there are no IMCs in the joint. The theoretical resistivity value equals to the ideal joint resistivity. The theoretical resistivity value $\left(\rho_{\text {th }}\right)$ can be calculated using Formula 5, where $\mathrm{f}_{\text {IMC }}=0$ in Formula 2. Obviously, the relationship among four kinds of resistivity follows the Formula 6.
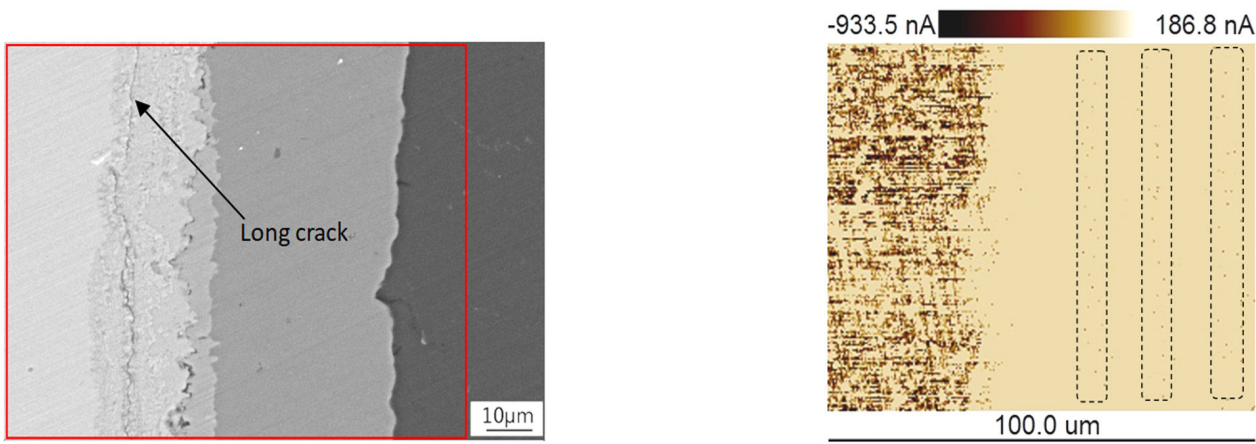

\section{(a)SEM}

(b)CAFM analysis result in the red rectangle of SEM image

Figure 8. Microstructure and current map of flash welded $\mathrm{Cu} / \mathrm{Al}$ joint after heat treatment at $350^{\circ} \mathrm{C}$ for $500 \mathrm{~h}$ : (a) SEM; (b) $\mathrm{CAFM}$ analysis result in the red rectangle of SEM image.

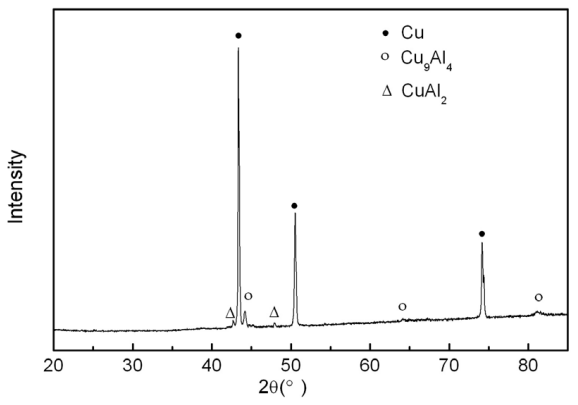

(a) $\mathrm{Cu}$ side

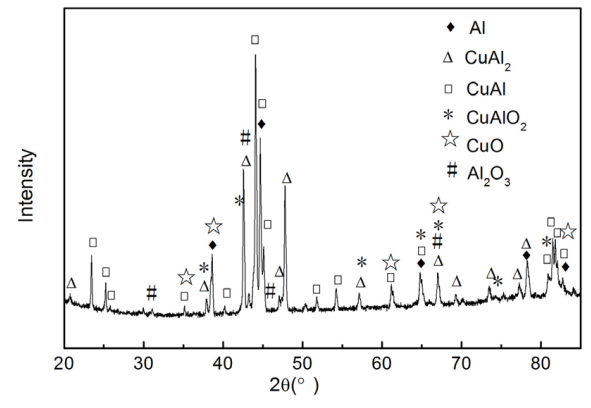

(b) Al side

Figure 9. $\mathrm{XRD}$ of flash welded $\mathrm{Cu} / \mathrm{Al}$ joint after heat treatment at $350^{\circ} \mathrm{C}$ for $500 \mathrm{~h}$ : (a)Cu side; (b) $\mathrm{Al}$ side. 


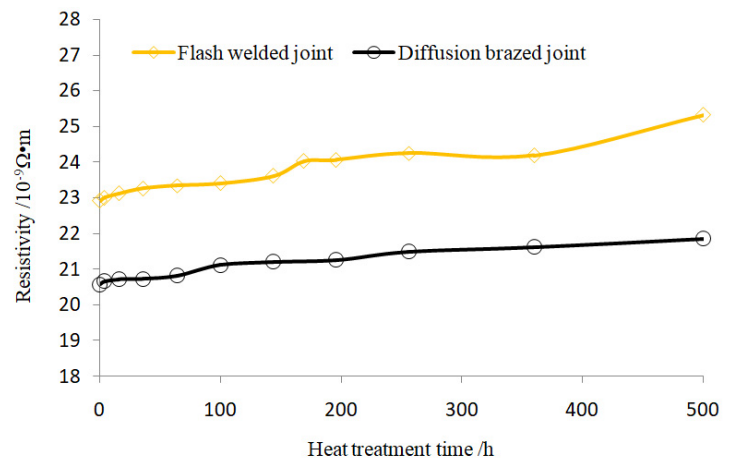

Figure 10. Variation of $\mathrm{Cu} / \mathrm{Al}$ joint resistivity with heat treatment time at $350^{\circ} \mathrm{C}$

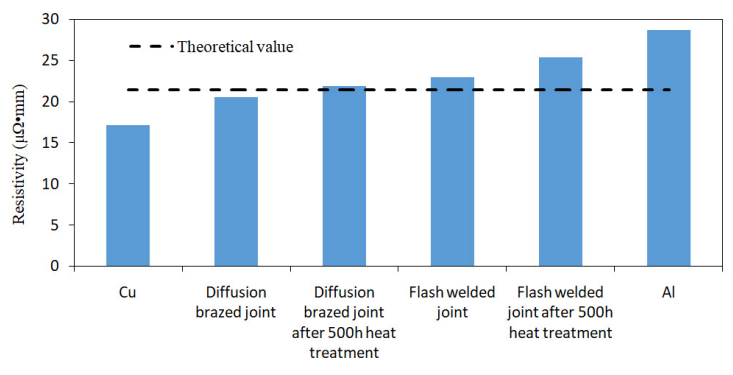

Figure 11. The electrical resistivity of $\mathrm{Cu} / \mathrm{Al}$ joints and base metals

$$
\begin{aligned}
& \rho_{C u}<\rho_{A l}<\rho_{I M C} \\
& \frac{1}{\rho_{t h}}=\frac{f_{A l}}{\rho_{A l}}+\frac{f_{C u}}{\rho_{C u}} \\
& \rho_{C u}<\rho_{t h}<\rho_{A l}<\rho_{I M C}
\end{aligned}
$$

Theoretically, the joint resistivity will be higher than the theoretical resistivity value when the IMCs present in the joint. By combining Formula 2 and Formula 7 to Formula 8 or Formula 9, the joint resistivity $\left(\rho_{\text {total }}\right)$ as a function of the volume fraction of IMCs and aluminum can be obtained. It can be seen that the joint resistivity will increase linearly withthe volume fraction of IMCs and aluminum. This is consistent with the result that a clear linear relation between resistivity and volume fraction of IMCs is found in the joint made by restacking drawing method ${ }^{12}$. As shown in Formula 8 , the joint resistivity $\left(\mathrm{f}_{\mathrm{IMC}}>0\right)$ is higher than the theoretical resistivity value $\left(f_{I M C}=0\right)$ as $\rho_{C u}-\rho_{I M C}<0$. Moreover, the joint resistivity will be higher than that of aluminum when $f_{\text {IMC }}$ is large enough. For example, both cold roll welded $\mathrm{Cu} /$ $\mathrm{Al}$ joint and laser beam welded $\mathrm{Cu}-\mathrm{Al}$ joint have higher resistivity than the theoretical resistivity value, but lower than that of aluminum ${ }^{2,23}$. The electrical resistivity of resistance projection welded joint is higher than the theoretical resistivity value $^{24}$. The resistivity of $\mathrm{Cu} / \mathrm{Al}$ composite is much higher than that of pure aluminum ${ }^{12}$. In this study, the interfacial IMCs are lamellar in both diffusion brazed and flash welded $\mathrm{Cu} / \mathrm{Al}$ joints. When the interfacial IMCs in $\mathrm{Cu} / \mathrm{Al}$ joint is lamellar, the volume fraction of the IMCs can be expressed using its thickness ratio due to the same faying surface area among copper, aluminum and IMCs, as shown in Formula 10. Similarly, the resistivity of $\mathrm{Cu} / \mathrm{Al}$ joints increases with the thickness increase of the IMCs, regardless of diffusion brazing or flash welding. Meanwhile, the thickness of IMCs is a few microns ( from $2 \mu \mathrm{m}$ to $50 \mu \mathrm{m}$ ) and the joint length using for resistance test is $100 \mathrm{~mm}$ in this work. According to Formula 10, the volume fraction of IMCs is very low. When there is extremely small $\mathrm{f}_{\mathrm{IMC}}$ value in Formula 9, the joint resistivity will be lower than that of aluminum because of $\rho_{\mathrm{Al}}-\rho_{\mathrm{Cu}}>0$. This is consistent with the experimental results that all the joints resistivity is less than that of aluminum as shown in Figure 11.

$$
\begin{aligned}
& f_{A l}+f_{C u}+f_{I M C}=1 \\
& \frac{1}{\rho_{\text {total }}}=\frac{1}{\rho_{C u}}+\frac{\rho_{C u}-\rho_{A l}}{\rho_{C u} \times \rho_{A l}} f_{A l}+\frac{\rho_{C u}-\rho_{I M C}}{\rho_{C u} \times \rho_{I M C}} f_{I M C} \\
& \frac{1}{\rho_{\text {total }}}=\frac{1}{\rho_{A l}}+\frac{\rho_{A l}-\rho_{C u}}{\rho_{C u} \times \rho_{A l}} f_{C u}+\frac{\rho_{A l}-\rho_{I M C}}{\rho_{A l} \times \rho_{I M C}} f_{I M C} \\
& f_{I M C}=\frac{\text { IMCs Thickness }}{\text { Joint length }}
\end{aligned}
$$

However, in practice, there are some abnormal cases in the relationship between joint resistivity and the thickness or the volume fraction of IMCs. The first case is that the joint resistivity is lower than the theoretical resistivity value. For example, the resistivity of friction stir spot welded joint is lower than the theoretical resistivity value, and even lower than that of copper ${ }^{13}$. The resistivity of the joint made by transient liquid phase bonding using Al-11Si-4Cu-2Mg was lower and close to the theoretical resistivity ${ }^{25}$. In this study, the resistivity of diffusion brazed joint is also lower than the theoretical resistivity. The second case is that the joint resistivity will not change with the volume fraction or thickness of IMCs. For example, the resistivity remains stable when the volume fraction of IMCs is below $12 \%$ in the $\mathrm{Cu} / \mathrm{Al}$ composite by a restacking drawing method ${ }^{11}$. The last case is that the experimental resistivity value is higher than the calculated value based on the Formula 2. For example, the actual resistivity value of cold roll welded joint in the absence of IMCs is higher than that of the calculated value ${ }^{2}$. In this study, the resistivity of flash welded joint with a thickness of $2 \mu \mathrm{m}$ IMCs is higher than the resistivity of the heat-treated diffusion brazed joint with a thickness of $50 \mu \mathrm{m}$ IMCs.

These actual abnormal cases indicate that the volume fraction or thickness of IMCs is not the only factor to affect the joint resistivity. Published literatures have shown that interfaces and engineering yield stress could impact electrical resistivity ${ }^{12}$. In addition to IMCs, the contact electrical resistance between copper and aluminum can be affected by contact area, oxides and stress ${ }^{26}$. Based on the SEM, CAFM and resistivity of joints, a model of electron motion across the interface of $\mathrm{Cu} / \mathrm{Al}$ is developed to explain this abnormal phenomenon, as shown in Figure 12. When a DC voltage is applied between copper and aluminum, a large number of electrons will move directionally from the aluminum side to the copper side. The directional flow of electrons forms a current. The magnitude of the current is related to the speed and the amount of electron movement. When the speed of electron movement is very fast, more 


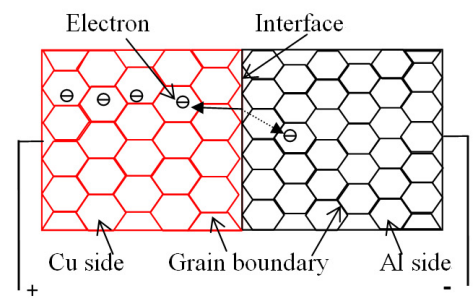

(a) an ideal joint without IMCs

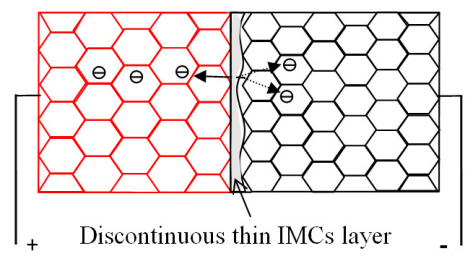

(c) $\mathrm{a} \mathrm{Cu} / \mathrm{Al}$ joint with discontinuous thin IMCs layer

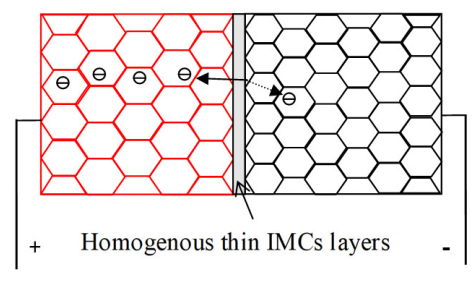

(b) a $\mathrm{Cu} / \mathrm{Al}$ joint with homogenous thin IMCs layer

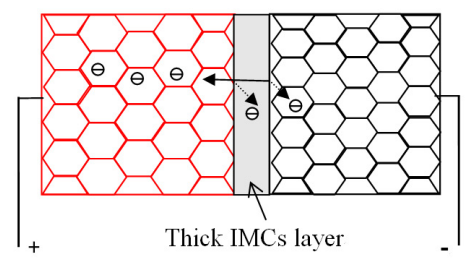

(d) a $\mathrm{Cu} / \mathrm{Al}$ joint with thick IMCs layer

Figure 12. Model of electron motion across the interface of $\mathrm{Cu} / \mathrm{Al}$ with and without IMCs layer: (a) an ideal joint without IMCs; (b) a Cu/ $\mathrm{Al}$ joint with homogenous thin IMCs layer; (c) a Cu/Al joint with discontinuous thin IMCs layer; (d) a Cu/Al joint with thick IMCs layer.

electrons will move from the aluminum side to the copper side per unit time, indicating that the current is large and the resistance to electron movement is very small. For an ideal $\mathrm{Cu} / \mathrm{Al}$ joint, there are no IMCs at the $\mathrm{Cu} / \mathrm{Al}$ interface. The valence electrons will move through the aluminum lattice, the $\mathrm{Cu} / \mathrm{Al}$ interface and the copper lattice. Copper and aluminum are metallic bonded metals. The valence electrons in the metallic bonds are not fixed in any one position. Under an applied voltage, these valence electrons can move easily and form a current. Therefore, metals with metallic bonds have excellent conductivity. In fact, the gaps between atomic layers are the movement paths of the valence electrons ${ }^{27}$. The reduction of lattice d-spacing can limit the movement space and increase the scattering of valence electrons by standing electrons and ions, which will lead to a decrease in electrical conductivity. In the work by Pouraliakbar $\mathrm{H}^{27}$, particles coarsening as well as lattice swelling can enhance the electrical conductivity by reducing the scattering of electrons. That is to say, the grain boundary has a great influence on the scattering of electrons. The $\mathrm{Cu}$ / $\mathrm{Al}$ interface is composed of copper grain boundaries and aluminum grain boundaries. The gaps at the $\mathrm{Cu} / \mathrm{Al}$ interface will be reduced by the mismatch of aluminum lattice and copper lattice. When electrons move to the $\mathrm{Cu} / \mathrm{Al}$ interface, the $\mathrm{Cu} / \mathrm{Al}$ interface will scatter the electrons. The number of electrons transferred through the interface per unit time is then reduced. At this time, the theoretical resistivity is introduced to characterize the effect of the interface on the movement of electrons, as shown in Figure 12a.

When there are IMCs at the $\mathrm{Cu} / \mathrm{Al}$ interface, the movement of valence electrons will change due to the difference in atomic bonding between IMCs and metals. Unlike the metallic bond of copper and aluminum, the atomic bonding of IMCs is a covalent bond. The valence electrons are locked in covalent bonds. The covalent bonds need be broken for valence electrons to be able to move.
Generally, high voltage or high temperature is required to provide more energy for electrons to overcome the energy gap $^{28}$. It is well known that the electric field force $(\mathrm{F})$ can be calculated by using Formula 11 .

$$
F=q \cdot E
$$

The electric field (E) is a result of applied voltage. For IMC with covalent bonds, when the electric field force is greater than the attraction of the nucleus, the electrons can break away from the attraction of the covalent bond and become freely moving electrons. Under the same electric field, copper or aluminum gives up valence electrons more easily than IMCs. IMCs will exist as an electron scattering agent and affect the movement of valence electrons in $\mathrm{Cu} / \mathrm{IMCs} / \mathrm{Al}$ structure. As noted by Pouraliakbar $\mathrm{H}^{27}$, the influence of electron scattering agent on electrical conductivity depends on its volume fraction. In this paper, the interfacial IMCs is lamellar. The influence of IMCs volume fraction on electron scattering can be discussed using its thickness. When the thickness of IMCs layer is lower than the grain size as shown in Figure 12b, the IMCs can be regarded as a wide grain boundary. The electrons can easily pass through the thin IMCs layer. Only one planar current distribution interface is formed by the scattering of electrons as shown in Figure 4b. Similar to that of an idea $\mathrm{Cu} / \mathrm{Al}$ joint, a few valence electrons are scattered by the thin IMCs layer. The resistivity will be close to the theoretical resistivity due to the similar electron scattering. While the thin IMCs layer becomes discontinuous, the contact area between electrons and $\mathrm{Al} / \mathrm{IMCs}$ is increased as shown in Figure 12c. More electrons will be scattered by the discontinuous thin IMCs layer, which will result in a non-planar current distribution interface, as shown in Figure 7b. As described in materials and method section, the electrical resistance was measured by passing a constant current of $200 \mathrm{~A}$ for all the joints. The current can be determined by Formula $12^{28}$. 
$I=n \cdot q \cdot \bar{v} \cdot S$

where I is direct current (200A), $\mathrm{n}$ is the number of valence electrons, $\mathrm{q}$ is the charge of electron $\left(1.6 \times 10^{-19} \mathrm{C}\right), \overline{\mathrm{v}}$ is the average drift velocity of electrons movement, $\mathrm{S}$ is the cross sectional area $(5 \mathrm{~mm} \times 12 \mathrm{~mm})$. Obviously, the product of the number of electrons and the drift velocity of electrons is constant under a constant current. Since a discontinuous IMCs layer scatters more valence electrons than a homogenous thin IMCs layer, the number of electrons is significantly reduced when valence electrons move through the discontinuous IMCs layer. The number of electrons or the drift velocity of electrons should be increased to keep the constant current. Then, a higher electric field is required to break the covalent bonds of IMCs for more valence electrons or speed up the electrons. The applied voltage is then increased with the increase of the electric field. The resistance of the joint with the discontinuous IMCs layer becomes larger. For a thick IMCs layer, the thickness of IMCs is close to the grain size, as shown in Figure 12d. It is difficult for electrons to pass through the thick IMCs layer. The thick IMCs will form more interfaces and increase the scattering of electrons, which leads to a multilayer current distribution as shown in Figure $6 \mathrm{~b}$ and Figure $8 \mathrm{~b}$. Meantime, more valence electrons should be given up through covalent bonds of IMCs in order to maintain the constant current. It can be seen from the formula (13) that the voltage (U) will increase as the electric field (E) or the thickness of IMCs layer (x) increases. Compared with thin IMCs layer, thick IMCs layer requires a higher voltage to give up valence electrons. Therefore, the resistivity of a joint with thick IMCs layer is higher than that of a joint with thin IMCs layer.

$$
U=E \cdot x
$$

In addition to IMCs, cracks and oxides will appear in $\mathrm{Cu} / \mathrm{Al}$ joints. Moreover, different welding methods will produce different residual stresses in the joint. These factors will also affect the transferring and scattering of electrons. Cracks can cut off the electron movement path and decrease largely the electronic conductivity. In this study, both short crack in Figure 6a and long crack in Figure 8a change the current distribution and lead to high resistivity. Oxides will reduce the movement speed of electrons since its resistivity is higher than that of IMCs. In this work, the flash welded $\mathrm{Cu} / \mathrm{Al}$ joint containing oxide has the highest resistivity among the four joints. Residual stress will be generated by the hot and cold cycles and pressure during welding process. Many published works have shown that the mobility of electron or ion in semiconductor films can be decreased by the compressive residual stress, resulting in high resistivity ${ }^{29-32}$. In rotary swaged $\mathrm{Cu} / \mathrm{Al}$ clad composites, the imposed strain by swaging can result in the directed material flow, which in turn leads to the direction flow of electrons and then increase the electrical conductivity ${ }^{33}$. In this paper, two different welding methods were used to join copper to aluminum. A thin layer of liquid between copper and aluminum were formed firstly below the melting point of aluminum $\left(660^{\circ} \mathrm{C}\right)$ for both welding methods. The thin layer of liquid was then extruded by welding pressure to

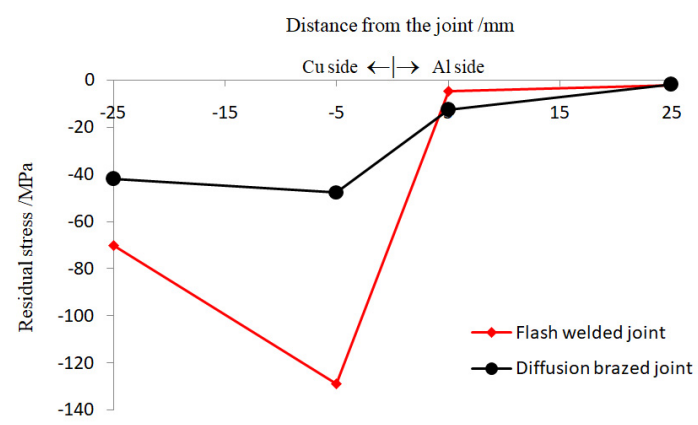

Figure 13. Residual stress across the $\mathrm{Cu} / \mathrm{Al}$ joints.

produce $\mathrm{Cu} / \mathrm{Al}$ joints. Different from the low deformation of diffusion brazing, flash welding can lead to huge deformation. The residual stress across the two joints was different owing to their different deformations, as shown in Figure 13. It can be seen that the residual stress of both joints is compressive stress. The compressive stress of flash welded joint is much higher than that of diffusion brazed joint. Although the phase type and thickness of interfacial IMCs in the two joints are the same, the morphology and residual stress are different. The discontinuous IMCs layer and the high residual compressive stress will reduce the movement speed of electrons and the transferring amount of electrons, resulting in high resistivity of flash welded joint. Heat treatment will remove the residual stress of the welded joints. The residual compressive stress of heat treated joints is lower than that of original joints. The resistivity of the flash welded joint ( $2 \mu \mathrm{m}$ IMCs) is still higher than the resistivity of the heat treated diffusion brazed joint (50 $\mu \mathrm{m}$ IMCs) due to the high residual compressive stress and discontinuous IMCs layer.

\section{Conclusion}

In this research, the longitudinal resistance and the lateral current distribution at flash welded and diffusion brazed $\mathrm{Cu} /$ Al joint interfaces were investigated to clarity the influence of IMCs on joint conductivity. The key conclusions were as follows:

1. A thin $\mathrm{Cu}_{9} \mathrm{Al}_{4} / \mathrm{CuAl}$ interfacial layer with thickness of $2 \mu \mathrm{m}$ was formed in both flash welded and diffusion joints. The IMCs layer was homogenous and the current distribution interface was planar at diffusion brazed joint. The IMCs layer was discontinuous and the current distribution interface was non-planar at flash welded joint.

2. The thickness of interfacial layer was increased to $50 \mu \mathrm{m}$ after heat treatment at $350^{\circ} \mathrm{C}$ for $500 \mathrm{~h}$. The interfacial layer was $\mathrm{Cu}_{9} \mathrm{Al}_{4} / \mathrm{CuAl} / \mathrm{CuAl}_{2}$ in the heat treated diffusion brazed joint and a short crack occurred in the middle of IMCs layer. The interfacial layer was $(\mathrm{Cu}, \mathrm{Al})_{\mathrm{x}} \mathrm{O}_{\mathrm{y}} / \mathrm{Cu}_{9} \mathrm{Al}_{4} / \mathrm{CuAl} /$ $\mathrm{CuAl}_{2}$ in the heat treated flash welded joint and a long crack occurred near the copper. A multilayer current distribution was found at both heat treated joints. The multilayer current distribution feature 
at heat treated diffusion brazed joint was more obvious than that at heat treated flash welded joint.

3. The resistivity of $\mathrm{Cu} / \mathrm{Al}$ joints with and without heat treatment was higher than that of copper and lower than that of aluminum. The resistivity of diffusion brazed joint was the lowest, which was lower than the theoretical value. The resistivity of the heat treated flash welded joint was the highest among all the joints. In addition to the thickness of IMCs, the morphology of IMCs, residual stress, crack and oxide scale also affected the electric resistivity of $\mathrm{Cu} / \mathrm{Al}$ joint.

\section{Acknowledgements}

The authors would like to acknowledge funding assistance provide by State Grid Corporation of China via Grant No.SGKJ[2010]14 and Shandong Jianzhu University via Grant No.X18063Z.

\section{References}

1. Zhang J, Wang BH, Che GH, Wang RM, Miao $\mathrm{CH}$, Zheng $\mathrm{ZX}$, et al. Formation and growth of Cu-Al IMCs and their effect on electrical property of electroplated $\mathrm{Cu} / \mathrm{Al}$ laminar composites. Trans Nonferrous Met Soc China. 2016;26:3283-91.

2. Abbasi M, Karimi Taheri A, Salehi MT. Growth rate of intermetallic compounds in $\mathrm{Al} / \mathrm{Cu}$ bimetal produced by cold roll welding process. J Alloys Compd. 2001;319:233-41.

3. Solchenbacha T, Plapper P, Cai W. Electrical performance of laser braze-welded aluminum-copperinterconnects, Journal of Manufacturing Processes. J Manuf Process. 2014;16:183-9.

4. Shin HS, De Leon M. Mechanical performance and electrical resistance of ultrasonic welded multiple $\mathrm{Cu}-\mathrm{Al}$ layers. J Mater Process Technol. 2017;241:141-53.

5. Braunovic M, Aleksandrov N. Intermetallic compounds at aluminum-to-copper and copper-to-tin electrical interfaces. In: 38th IEEE Holm Conference on Electrical Contacts; 1992 Oct 18-21; Philadelphia, PA. Proceedings. Philadelphia, PA: IEEE; 1992. p. 25-34.

6. Braunovic M, Aleksandrov N. Effect of electrical current on the morphology and kinetics of formation of intermetallic phase in bimetalc aluminum copper joints. In: IEEE Holm Conference on Electrical Contacts; 1993 Sept 27-29; Pittsburgh, PA. Proceedings. Philadelphia, PA: IEEE; 1993. p. 261-268.

7. Braunovic M, Alexandrov N. Intermetallic compounds at aluminium-to-copper electrical interfaces: effect of temperature and electric current. IEEE Trans Compon Packag Manuf Tech. 1994;17(1):78-85.

8. Khanzadeh Gharah Shiran MR, Khalaj G, Pouraliakbar H, Jandaghi MR, Soltani Dehnavi A, Bakhtiari H. Multilayer Cu/Al/ $\mathrm{Cu}$ explosive welded joints: characterizing heat treatment effect on the interface microstructure and mechanical properties. J Manuf Process. 2018;35:657-63.

9. Matsuoka SI, Imai H. Direct welding of different metals used ultrasonic vibration. J Mater Process Technol. 2009;209:954-60.

10. Wang XG, Yan FJ, Li XG, Wang CG. Induction diffusion brazing of copper to aluminium. Sci Technol Weld Join. 2017;22(2):170-5.

11. Honarpisheh M, Asemabadi M, Sedighi M. Investigation of annealing treatment on the interfacial properties of explosive-welded $\mathrm{Al} / \mathrm{Cu}$ / Al multilayer. Mater Des. 2012;37:122-7.

12. Moisy F, Gueydan A, Sauvage X, Guillet A, Keller C, Guilmeau $\mathrm{E}$, et al. Influence of intermetallic compounds on the electrical resistivity of architectured copper clad aluminum composites elaborated by arestacking drawing method. Mater Des. 2018;155:36674.
13. Mubiayi MP, Akinlabi ET, Makhatha ME. Microstructure and electrical resistivity properties of copper and aluminium frictionstir spot welds. In: 8th International Conference on Mechanical and Intelligent Manufacturing Technologies; 2017 Feb 3-6; Cape Town, South Africa. 2017, p. 42-47.

14. Reisgen U, Olschok S, Jakobs S, Holtum N. Influence of the degree of dilution with laser beam vacuum-welded $\mathrm{Cu}-\mathrm{Al}$ mixed joints on the electrical properties. Procedia CIRP. 2018;74:23-6.

15. Bhamji I, Moat RJ, Preuss M, Threadgill PL, Addison AC, Peel MJ. Linear friction welding of aluminium to copper. Sci Technol Weld Join. 2012;17(4):314-20.

16. Shankar S, Vilaça P, Dash P, Chattopadhyaya S, Hloch S. Joint strength evaluation of friction stir welded Al-Cu dissimilar alloys. Measurement. 2019;146:892-902.

17. Wei L, Yin YF, Zhang WF. Utilization of a cross-section CAFMto investigate resistive switching behaviorsin a $\mathrm{Pt} / \mathrm{YMnO} / \mathrm{Pt}$ device. J Phys D Appl Phys. 2016;49:455302-11.

18. Zhu Z, Chen YQ, Luo AA, Liu LH. First conductive atomic force microscopy investigation on the oxide-film removal mechanism by chloride fluxes in aluminum brazing. Scr Mater. 2017;138:12-6.

19. Kumar A, Kapoor R, Garg M, Kumar V, Singh R. Direct evidence of barrier inhomogeneities at metal/AlGaN/GaN interfaces using nanoscopic electrical characterizations. Nanotechnology. 2017;28(26):72-5.

20. Sharma I, Mehta BR. KPFM and CAFM based studies of MoS2 (2D)/WS2 heterojunction patterns fabricated using stencil mask lithography technique. J Alloys Compd. 2017;723:50-7.

21. Wang XG, Li XG, Yan FJ, Wang CG. Effect of heat treatment on the interfacial microstructure and properties of $\mathrm{Cu}-\mathrm{Al}$ joints. Weld World. 2017;61:187-96.

22. Wang XG, Li XG, Wang CG. Influence of diffusion brazing parameters on microstructure and properties of $\mathrm{Cu} / \mathrm{Al}$ joints. $\mathrm{J}$ Manuf Process. 2018;35:343-50.

23. Reisgen U, Olschok S, Holtum N. Influencing the electrical properties of laser beamvacuum-welded $\mathrm{Cu}-\mathrm{Al}$ mixed joints. J Laser Appl.2019;31(022406):1-6.

24. Gintrowski G, Reisgen U, Schiebahn A, Schmechtenberg M, Hibert V. Characteristics of resistance projection-weldedaluminum-copper interconnects. Weld World. 2019;63:1593-9.

25. Wei YN, Sun F, Tan SY, Liang SH. Study on microstructure and performance of transient liquid phase bondingof $\mathrm{Cu} / \mathrm{Al}$ with $\mathrm{Al}-$ based interlayers. Vacuum. 2018;154:18-24.

26. Braunovic M. Reliability of power connections. J Zhejiang Univ Sci A. 2007;8(3):343-56.

27. Pouraliakbar H, Jandaghi MR, Khalaj G. Constrained groove pressing and subsequent annealing of Al-Mn-Sialloy: microstructure evolutions, crystallographic transformations, mechanical properties, electrical conductivity and corrosion resistance. Mater Des. 2017; 124:34-46.

28. Askeland DR, Phulé PP, editors. The science and engineering of materials. California: Brooks/Cole Thomson learning; 2003.

29. Choi SK, Lee JI. Effect of film density on electrical properties of indium tinoxide films deposited by dc magnetron reactive sputtering. J Vac Sci Technol A. 2001;19(5):2043-7.

30. Mahmood A, Ahmed N, Raza Q, Muhammad Khan T, Mehmood M, Hassan MM, et al. Effect of thermal annealing on the structural and optical properties of $\mathrm{ZnO}$ thin films deposited by the reactive e-beam evaporationtechnique. Phys Scr. 2010;82(065801):1-8.

31. Kumar M, Sigdel AK, Gennettc T, Berry JJ, Perkins JD, Ginley DS, et al. Optimizing amorphous indium zinc oxide film growth for lowresidual stress and high electrical conductivity. Appl Surf Sci. 2013;283:65-73

32. Yeh TH, Lin RD, Cherng JS. Effects of residual stress and interface dislocations on the ionicconductivity of yttria stabilized zirconia nano-films. Thin Solid Films. 2016;574:66-70.

33. Kocich R, Kunčická L, Macháčková A, Šofer M. Improvement of mechanical and electrical properties of rotary swagedAl-Cu clad composites. Mater Des. 2017;123:137-46. 